Supporting Information

\title{
Unusually High Ion Conductivity in Large-Scale Patternable Two-Dimensional MoS 2 Film
}

\author{
Juhong Park ${ }^{1 \dagger}$, Sanket Bhoyate ${ }^{1 \dagger}$, Young-Hoon Kim***, Young-Min Kim ${ }^{* *, 8}$, Young Hee Lee ${ }^{\S}$, \\ Patrick Conlin ${ }^{*}$, Kyeongjae Cho ${ }^{*}$, Wonbong Choi ${ }^{\dagger *}$ \\ †Department of Materials Science and Engineering, University of North Texas, \\ Denton, Texas 76203, United States \\ tDepartment of Mechanical and Energy Engineering, University of North Texas, \\ Denton, Texas 76203, United States \\ * Department of Materials Science and Engineering, University of Texas at Dallas, \\ Richardson, Texas 75080, United States \\ * Department of Energy Science, Sungkyunkwan University, \\ Suwon 16419, Republic of Korea \\ ${ }^{\S}$ Center for Integrated Nanostructure Physics, Institute for Basic Science (IBS), Suwon \\ 16419, Republic of Korea
}

*Corresponding author: wonbong.choi@unt.edu; J. P. and S.B. contributed equally to this work. 


\section{Note S1: Calculations for ion conductivity}

To obtain the relative ionic fraction in the total conductance in a solid, a quantitative analysis of the concentration and conductivity was utilized. The total conductance measured from the $\mathrm{MoS}_{2}$ film on a quartz substrate was considered as the sum of four components: (1) electronic conductance of the quart $\left(\mathrm{G}_{\mathrm{e}}\right.$, quartz), (2) ionic conductance of the quartz $\left(\mathrm{G}_{\mathrm{i}}\right.$, quartz), (3) electronic

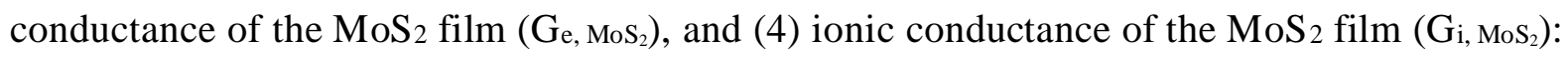

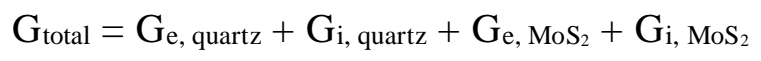

The $\mathrm{Ge}_{\mathrm{e}}$, quartz of the quartz substrate is very low and negligible because the quartz is a naturally insulating material. Both $\mathrm{G}_{\mathrm{i}}$, quartz, and $\mathrm{G}_{\mathrm{e}}, \mathrm{MoS}_{2}$ are experimentally measured to confirm that the majority of conductivity comes from ion flow.

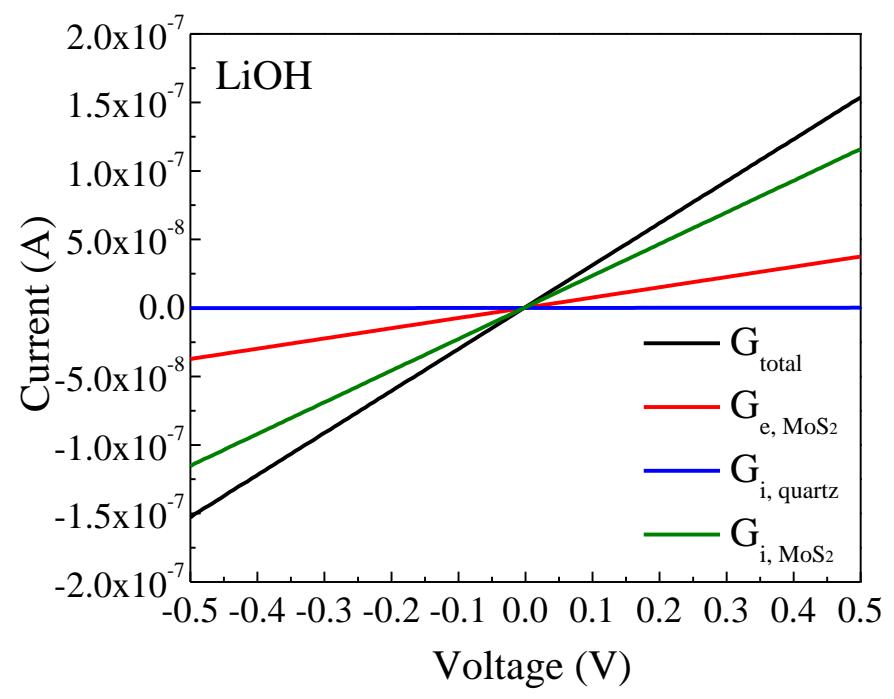

The above figure shows the current-voltage (I-V) characteristics of $4.1 \mathrm{~nm}$ thick $\mathrm{MoS}_{2}$ on the quartz substrate with $0.01 \mathrm{M} \mathrm{LiOH}$ solution. To measure the ionic current across $\mathrm{MoS}_{2}$ film, we subtracted $\mathrm{G}_{e}, \mathrm{MoS}_{2}$ from the total measured current $\left(\mathrm{G}_{\text {total }}\right)$. The $\mathrm{G}_{e}$, MoS2 data was obtained by using deionized (DI) water, excluding ionic current. For measuring $\mathrm{G}_{\mathrm{i}}$, quartz, we used different concentrations of $0.01 \sim 0.003 \mathrm{M}$ electrolytes. We found that there was no current blow $0.003 \mathrm{M}$ concentration. The measured currents at $0.01 \mathrm{M} \mathrm{LiOH}, \mathrm{NaOH}$, and $\mathrm{KOH}$ concentrations are comparable to the reported values observed using $\mathrm{LiCl}, \mathrm{NaCl}$, and $\mathrm{KCl}$ solutions. ${ }^{1,2}$ 


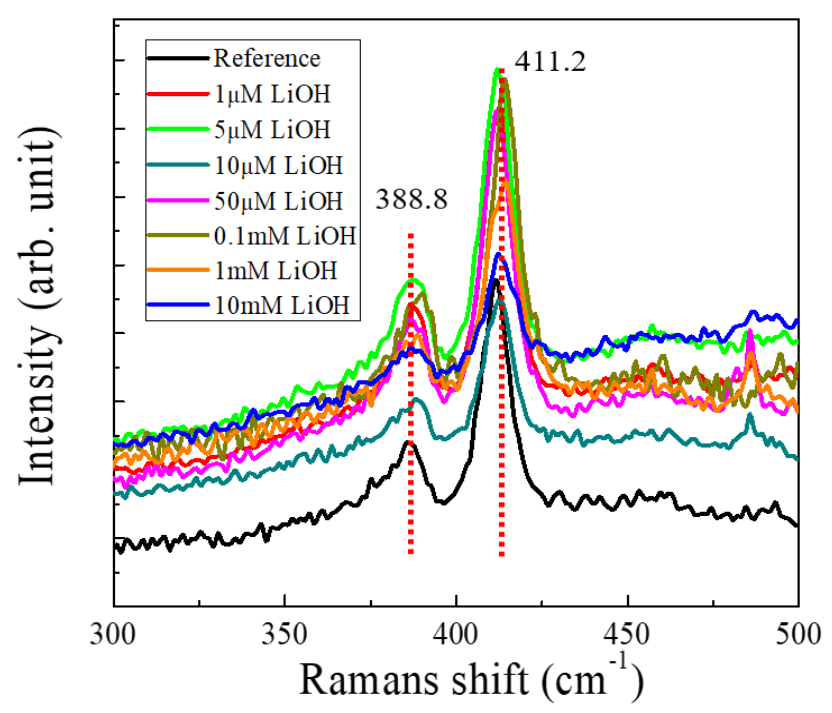

According to the Raman spectra of $\mathrm{MoS}_{2}$ film after ion flow measurement using $10 \mathrm{mM} \sim 1 \mu \mathrm{M}$ concentrations of $\mathrm{LiOH}$, the crystal structure of $\mathrm{MoS}_{2}$ film reveals a stable $2 \mathrm{H}$ semiconducting phase. Therefore, the electronic current of $\mathrm{MoS}_{2}$ film is regarded as a constant value. This analysis method has been reported to confirm a specific species from the total current transported in a single channel material. ${ }^{3,4}$

Based on the above calculation, the ionic conductance for the $\operatorname{MoS}_{2}$ film $\left(\mathrm{G}_{\mathrm{i}, \mathrm{MoS} 2}\right)$ was measured. The ionic conductivity $(\lambda)$ at the various ionic solutions was calculated from below the equation:

$$
\lambda=\mathrm{G}(1 / \mathrm{hw})
$$

where $\mathrm{G}$ is the measured ionic conductance and $\mathrm{l}, \mathrm{h}$, and $\mathrm{w}$ are the length, height (thickness), and width of the channel, respectively. Length and width were taken from the measured physical dimension of the nanochannels. The ionic conductivities of three different electrolytes were obtained from several measurements taken at three devices (Figure S2) with four different $\mathrm{MoS}_{2}$ film thicknesses (Figure S3). 


\section{Note S2: Ion flow calculations from conductivity data}

The current flow through the open channel can be described using the Ohms law relationship as: ${ }^{5}$

$$
i=\sigma \mathrm{Vm}_{\mathrm{m}}
$$

where $i$ is the total current flow through the channel in amperes, $V_{m}$ is the total electrical potential across the nanochannel membrane in volts and $\mho$ is the conductivity in Siemens. ${ }^{5}$

The measured ion conductivity in the $\mathrm{MoS}_{2}$ nanofilm is presented in Figure $2 \mathrm{~b}$. The value of conductance ( $\widetilde{O})$ solely depends upon the movement of charges and represents the ions transferred through the channel after subtraction of current from any other components.

An example of calculations for ion conductivity is presented below:

$$
\begin{gathered}
1 \mathrm{pA}=\left(10^{12} \mathrm{C} / \mathrm{s}\right) \times\left(1 \text { mole } \mathrm{K}^{+} / 96,500 \mathrm{C}\right) \times\left(\sim 10^{23} \text { ions } / \mathrm{mole}\right) \\
1 \mathrm{pA}=\sim 10^{6} \mathrm{~K}^{+} \text {ions } / \mathrm{s}
\end{gathered}
$$

The values for $\mathrm{K}^{+}$ion flow per second have been calculated based on the ion conductivity data and presented in Figure 2c. Calculation can be detailed as follows:

The current value obtained at $0.01 \mathrm{M} \mathrm{KOH}$ concentration and constant volatage of $0.5 \mathrm{~V}$ was 9.14 x $10^{-8} \mathrm{~A}$. Therefore, the ion flow rate can be calculated as: $\left(9.14 \times 10^{-8} \mathrm{~A}\right) \times\left(\left(\sim 10^{6} \mathrm{~K}^{+}\right.\right.$ions/s $) /$ $1 \mathrm{pA})$

$=9.14 \times 10^{10} \mathrm{~K}^{+}$ions $/ \mathrm{s}$.

Similarly, the flow rate for $\mathrm{Na}^{+}$and $\mathrm{Li}^{+}$ions can be calculated. 
Table S1: Calculated ion flow based on $\mathrm{pH}$ change in the $\mathrm{MoS}_{2}$ nanochannel device.

\begin{tabular}{|c|c|c|c|c|c|}
\hline $\begin{array}{c}\text { KOH Conc. } \\
\text { At side A }\end{array}$ & Time & Ion Flow & $\begin{array}{c}\text { pH change } \\
\text { (Side A) }\end{array}$ & $\begin{array}{c}\text { KOH Conc. } \\
\text { At side B }\end{array}$ & $\begin{array}{c}\text { pH change } \\
\text { (Side B) }\end{array}$ \\
\hline & $0 \mathrm{~s}$ & 0 & 12 & 0 & 7 \\
\cline { 2 - 6 } & $5 \mathrm{~s}$ & $4.57 \times 10^{11}$ & $\sim 12$ & $7.6 \times 10^{-7} \mathrm{M}$ & 7.88 \\
\cline { 2 - 6 } $0.01 \mathrm{M}$ & $10 \mathrm{~s}$ & $9.14 \times 10^{11}$ & $\sim 12$ & $1.52 \times 10^{-6} \mathrm{M}$ & 8.18 \\
\cline { 2 - 6 } & $20 \mathrm{~s}$ & $1.83 \times 10^{12}$ & $\sim 12$ & $3.04 \times 10^{-6} \mathrm{M}$ & 8.48 \\
\cline { 2 - 6 } & $60 \mathrm{~s}$ & $5.48 \times 10^{12}$ & $\sim 12$ & $9.1 \times 10^{-6} \mathrm{M}$ & 8.95 \\
\hline
\end{tabular}




\section{Note S3: Calculation of the ion flow by measuring pH change}

Figure 2a shows the schematic of the $\mathrm{MoS}_{2}$ device for ion transport study. Firstly, we measured the I-V characteristics to obtain the ion conductivity and ion flow rate as shown in Figure $2 \mathrm{~b}$ and Figure 2c, and the detailed calculations are explained in Note S2. To understand the ion flow behavior across the $\mathrm{MoS}_{2}$ film, we measured the $\mathrm{pH}$ change at side $\mathrm{A}(100 \mu \mathrm{L}$ of $0.01 \mathrm{M} \mathrm{KOH})$ and side $\mathrm{B}(100 \mu \mathrm{L}$ of $0.01 \mathrm{M} \mathrm{KCl})$ at different time intervals (Figure 2e). As we apply the constant voltage of $0.5 \mathrm{~V}$, the ion concentration on side A decreases while that on side B increases line arly with time (Figure 2d).

The total number of $\mathrm{K}^{+}$ions in $100 \mu \mathrm{L}$ of $0.01 \mathrm{M} \mathrm{KOH}$ solution can be calculated as,

$=\mathrm{N}_{\mathrm{a}} \times \mathrm{C}_{\mathrm{m}} \times \mathrm{Q}_{\mathrm{m}}$

where the $\mathrm{N}_{\mathrm{a}}$ is Avogadro's number of ions per mol, $\mathrm{C}_{\mathrm{m}}$ is the molar concentration of $\mathrm{K}^{+}$ions, and $\mathrm{Qm}_{\mathrm{m}}$ is the quantity of electrolyte.

$=6.022 \times 10^{23}(\mathrm{ions} / \mathrm{mol}) \times 0.01(\mathrm{~mol} / \mathrm{L}) \times 0.0001 \mathrm{~L}=6.022 \times 10^{17}$ ions

The change in the number of ions from side A to side B can be calculated based on the flow rate shown in Figure 2c. Based on these values, the $\mathrm{pH}$ of the solutions can be determined using:

$$
\mathrm{pH}+\mathrm{pOH}=14
$$

The calculated $\mathrm{pH}$ change using the ion conductance of $\mathrm{MoS}_{2}$ film is shown in Figure 2e, and the $\mathrm{pH}$ change was confirmed by measuring the color change of $\mathrm{pH}$ strips from side $\mathrm{A}$ and $\mathrm{B}$ (Figure $2 \mathrm{~g}$ ). The accuracy of $\mathrm{pH}$ strips was further confirmed by using a $\mathrm{pH}$ meter. As shown in Figure $2 \mathrm{f}$, the $\mathrm{pH}$ of $0.01 \mathrm{M} \mathrm{KOH}$ solution is 12 , and $0.01 \mathrm{M} \mathrm{KCl}$ solution is 7 . Based on our calculations in Figure $2 \mathrm{e}$, the $\mathrm{pH}$ change in side $\mathrm{B}$ is more vivid in the beginning, and eventually it reaches a plateau with time. This is because $\mathrm{pH}$ is a logarithmic scale and a large number of ions are necessary to induce $\mathrm{pH}$ change at higher $\mathrm{pH}$ values. For the $\mathrm{pH}$ change from 7 to 8 at a constant flow rate of $9.14 \times 10^{10}$ ions/s (calculated based on conductivity data explained in Note S2), a small number of ions $\left(\sim 9.14 \times 10^{11} \mathrm{~K}^{+}\right)$need to be transported from side $\mathrm{A}$ to $\mathrm{B}$, which takes a very short time of $10 \mathrm{~s}$ shown in the calculation below:

i) $\mathrm{KOH}$ conc. necessary for $\mathrm{pH}=8$ is $1.52 \times 10^{-6} \mathrm{M}$.

ii) No. of $\mathrm{K}^{+}$ions necessary to produce $\mathrm{pH}=8$ are $9.14 \times 10^{11}$ ions. 
iii) Time required for ion flow $=\frac{\text { No of ions necessary for } \mathrm{pH}=8}{\text { Flow rate }}=\frac{9.14 \times 10^{11} \text { ions }}{9.14 \times 10^{10} \text { ions } / \mathrm{s}}=10 \mathrm{~s}$.

However, for $\mathrm{pH}$ change from 11 to $12, \sim 5.69 \times 10^{17} \mathrm{~K}^{+}$ions need to be transported from side A to $\mathrm{B}$, which will take a very long time period of $\sim 6.24 \times 10^{6} \mathrm{~s}$. Our study shows modulation of $\mathrm{pH}$ in the solution of side $\mathrm{B}$ by controlling the $\mathrm{K}^{+}$ion flow with time. 


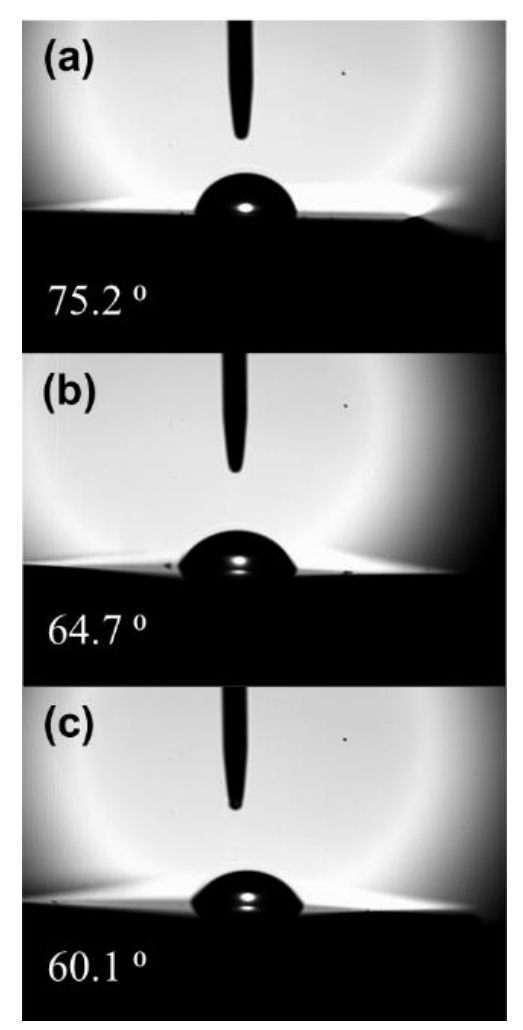

Figure S1. Contact angle measurements of the $\mathrm{MoS}_{2}$ membrane on the quartz substrate for (a) 0.8 $\mathrm{nm} \mathrm{MoS}$, (b) $4.1 \mathrm{~nm} \mathrm{MoS}$, and (c) $6.4 \mathrm{~nm} \mathrm{MoS}$, respectively, showing that the $\mathrm{MoS}_{2}$ has a hydrophilic surface. Our study shows that the single-layer $\mathrm{MoS}_{2}$ on the quartz substrate has a contact angle of $75.2^{\circ}$ comprehending the wetting properties of deposited $\mathrm{MoS}_{2}$ samples are solely dependent on the surface property of $\mathrm{MoS}_{2}$ membrane as the contact angle for the bare quartz substrate is measured to be $<5^{\circ}{ }^{6}$ In addition to this, the arrangement of $\mathrm{MoS}_{2}$ layers also affects the hydrophilicity of the membrane, i.e. the edge sites in $\mathrm{MoS}_{2}$ are hydrophilic, while the basal plane sites are hydrophobic in nature. ${ }^{7}$ As observed from the HRTEM analysis (Figure 1e), increasing the thickness of the $\mathrm{MoS}_{2}$ film results in the lattice orientation change of $\mathrm{MoS}_{2}$ grains exposing their edge sites, therefore, reducing the contact angle. 

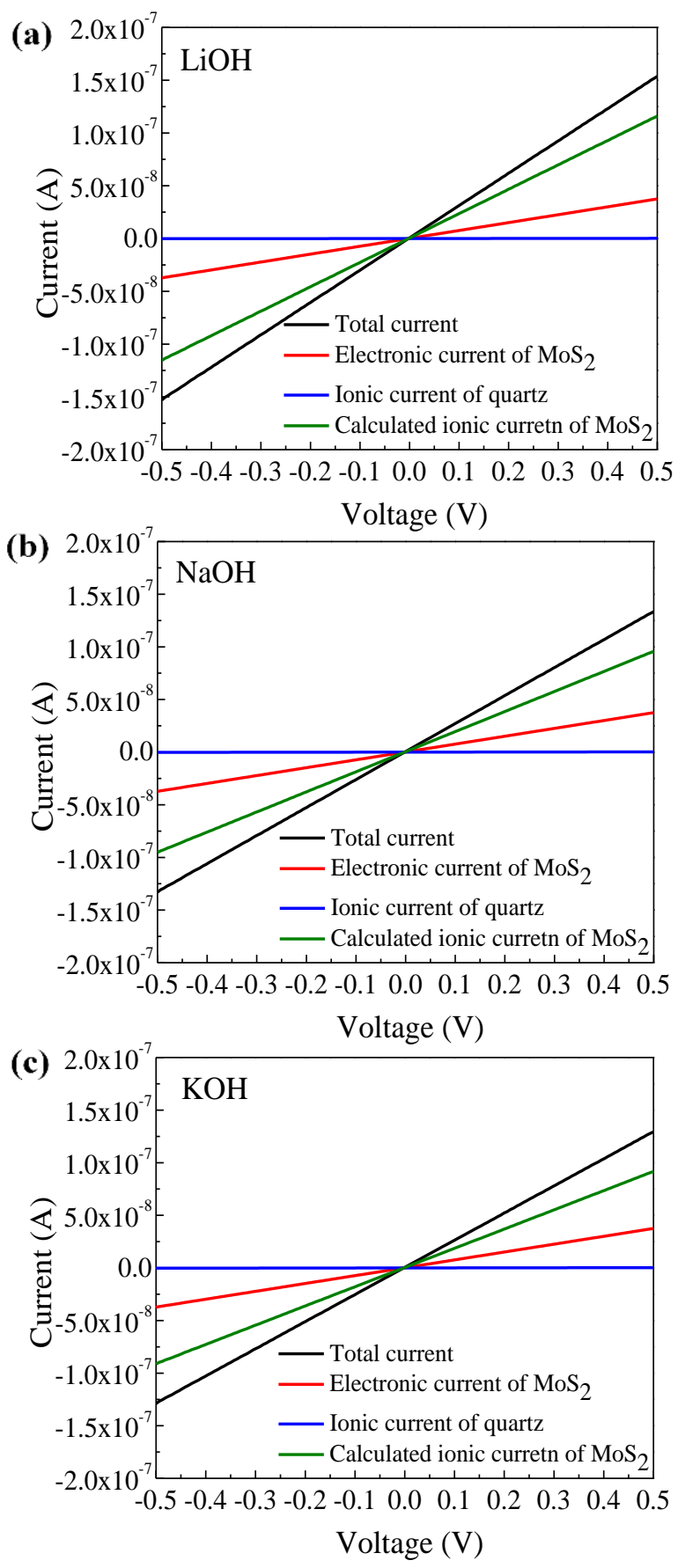

Figure S2. Source-drain voltage $v$ s. current curve $\left(\mathrm{I}_{d}-\mathrm{V}_{\mathrm{d}}\right)$ of $4.1 \mathrm{~nm}$-thick $\mathrm{MoS}_{2}$ film with (a) $0.01 \mathrm{M}$ $\mathrm{LiOH}$, (b) $0.01 \mathrm{M} \mathrm{NaOH}$, and (c) $0.01 \mathrm{M} \mathrm{KOH}$. The total current (black curve) and other components of current, such as an electronic current of the $\mathrm{MoS}_{2}$ film (red curve) and ionic current of the quartz substrate (blue curve) measured with DI water and ionic solution, separately. The ionic current of the $\mathrm{MoS}_{2}$ film (green curve) could be obtained by subtracting the electronic current of the $\mathrm{MoS}_{2}$ film and the ionic current of the quartz from the measured current. It is noted that the ionic current of $\mathrm{MoS}_{2}$ film is much higher than any current component in $\mathrm{MoS}_{2}$. 

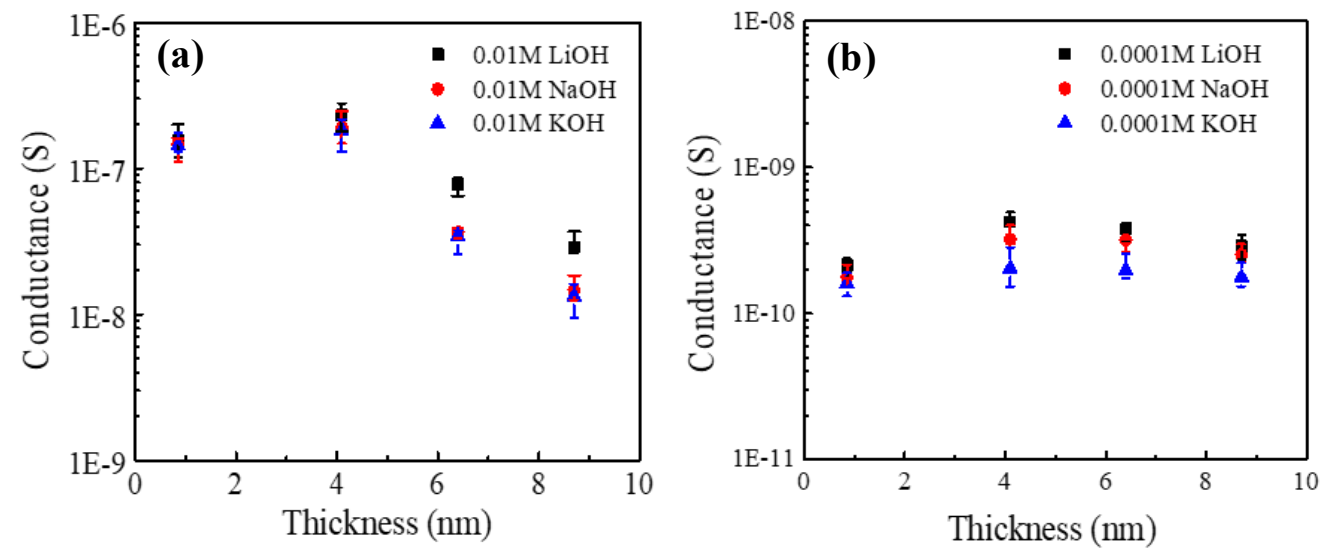

Figure S3. Statistical analysis of ion conductance of the $\mathrm{LiOH}, \mathrm{NaOH}$, and $\mathrm{KOH}$ at different ion concentration (a) $10 \mathrm{mM}$ and (b) $0.1 \mathrm{mM}$ measured through different thicknesses of $\mathrm{MoS}_{2}$ nanofilm. The $4.1 \mathrm{~nm} \mathrm{MoS} 2$ membrane exhibits the highest ionic conductance. Each data point was measured from at least three devices, and the measured data are consistent. 


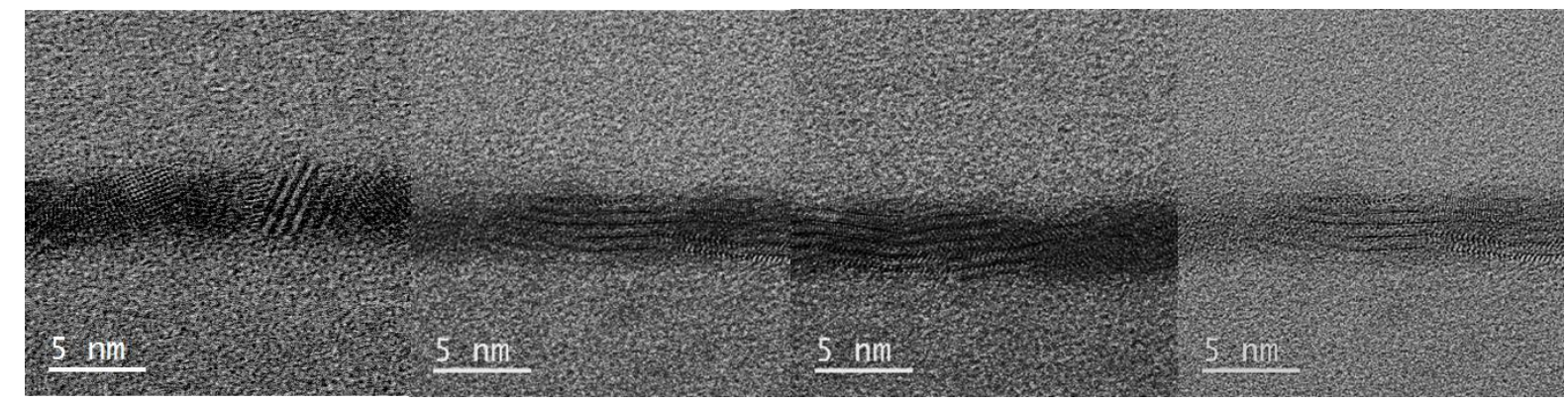

Figure S4. The cross-sectional HRTEM image of 4.1nm-thick $\mathrm{MoS}_{2}$ film showing a layered structure of the polycrystalline $\mathrm{MoS}_{2}$ with having few tilted grains. 

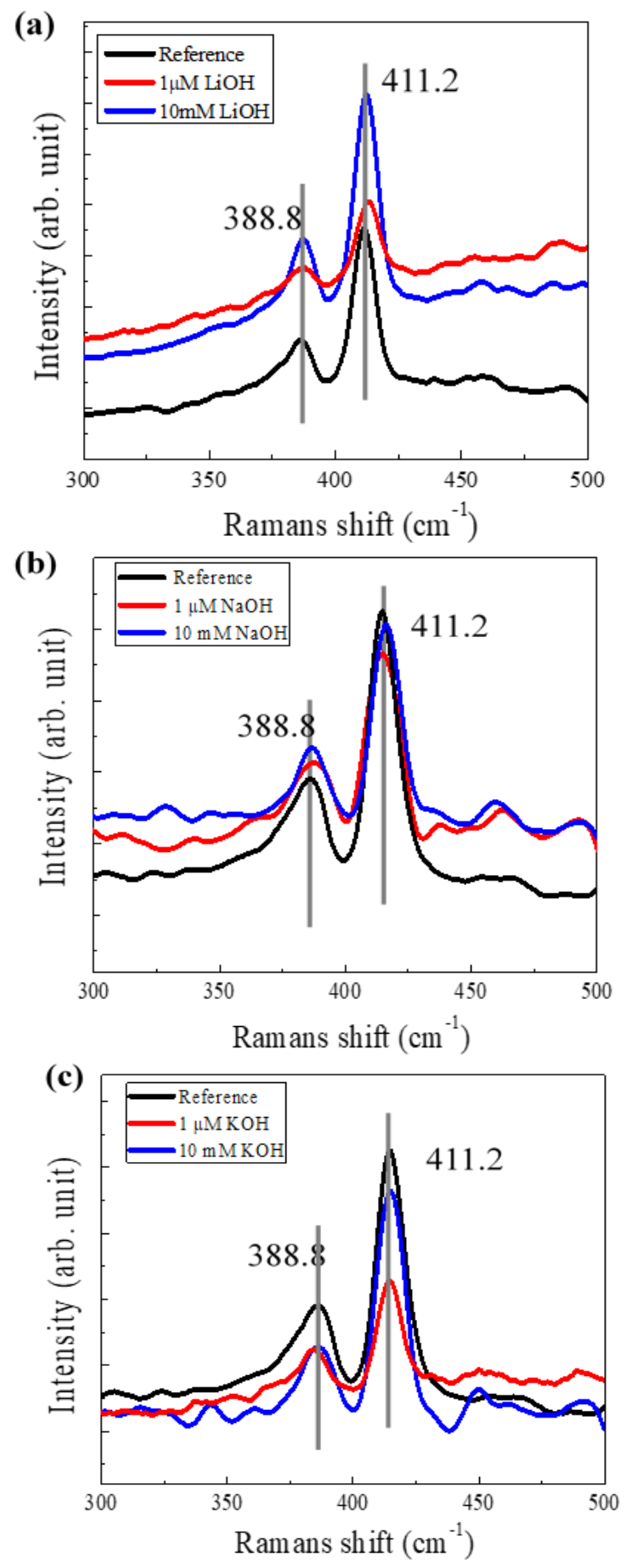

Figure S5. Raman spectra of $\mathrm{MoS}_{2}$ film before (Reference) and after ion flow study using $10 \mathrm{mM}$ and $1 \mu \mathrm{M}$ concentration of (a) $\mathrm{LiOH}$, (b) $\mathrm{NaOH}$, and (c) $\mathrm{KOH}$ electrolyte. The Raman spectra for the $\mathrm{MoS}_{2}$ film exhibit that the crystal structure of $\mathrm{MoS}_{2}$ is remained with a stable $2 \mathrm{H}$ phase before and after the ion conductivity measurement suggesting that the ion flow does not affect the crystallinity of $\mathrm{MoS}_{2}$. 


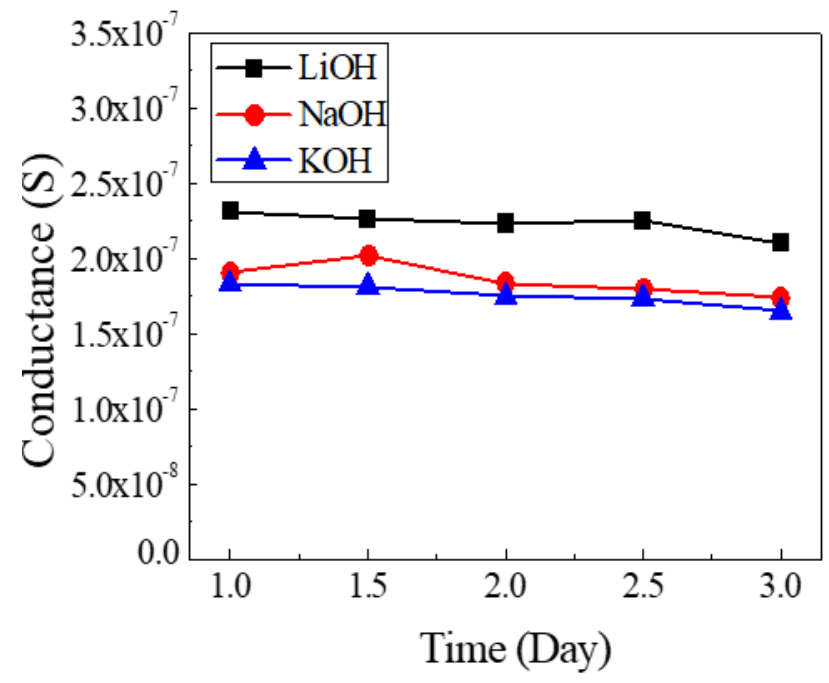

Figure S6. Variation of ion conductivity of $\mathrm{MoS}_{2}$ nanochannel measured for 3 days in $0.01 \mathrm{M}$ $\mathrm{LiOH}, \mathrm{NaOH}$, and $\mathrm{KOH}$ ionic solution. The graph confirms the reliability of ion conductivity with time in the $\mathrm{MoS}_{2}$ membrane. 


\section{Note S4. DFT simulation}

Density functional theory was used to investigate the effects of confining geometry on the diffusion behavior of $\mathrm{Li}, \mathrm{Na}, \mathrm{K}$ in $2 \mathrm{H} \mathrm{MoS}$. First, diffusion was modeled along with different facets of a $2 \mathrm{H} \mathrm{MoS} 2$ monolayer flake. The different pathways considered for this study are depicted in Figure S7. The resultant barriers are plotted in Figure S8 and summarized in Table S2. In this environment, mobility is inversely proportional to ion size (so Li has the lowest mobility). However, this model does not accurately reflect the internal geometry of the real sample. Therefore, the grain boundary model shown in the main text was designed. Except for Li ions, diffusion of $\mathrm{Na}$ and $\mathrm{K}$ ions into van der Waals interlayer gaps can result in a noticeable change in interlayer distance. However, based on our HRTEM and Raman analysis (Figure 4), we did not observe any noticeable change in interlayer distance and conclude that the interlayer diffusion mechanism does not apply to our experimental samples with ions transporting within the film. The polycrystallinity of our $\mathrm{MoS}_{2}$ film creates the possibility of unique ion pathways via free surfaces at grain boundaries. Specifically, we calculated the DFT energy curve with respect to the separation distance between the two $\mathrm{MoS}_{2}$ grains (Figure S10). At the optimized inter-grain distance, we found that a percolated one-dimensional ion transport pathway around the grain boundaries results in an ion flow within our $\mathrm{MoS}_{2}$ film (Figure 3). This finding is consistent with experimental confirmation via the ADF-HRTEM analysis, as shown in Figure 4. 
(a)

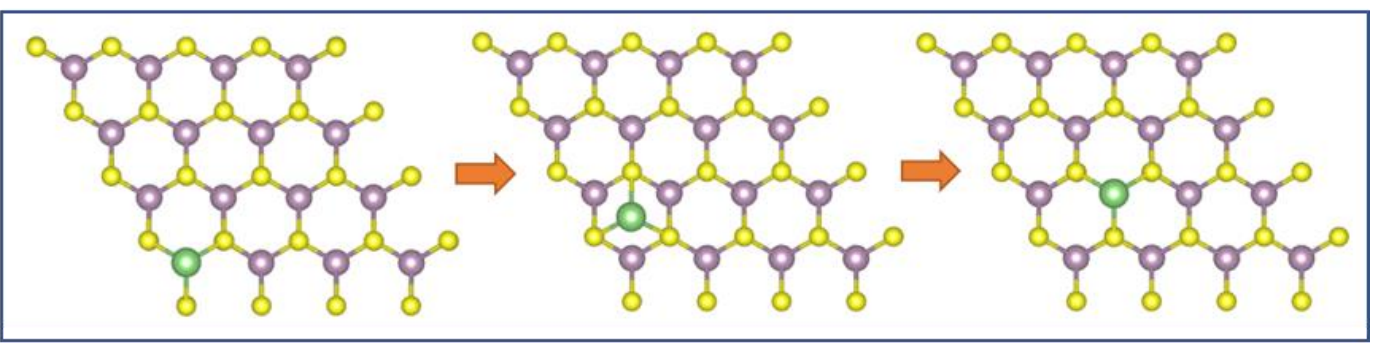

(b)

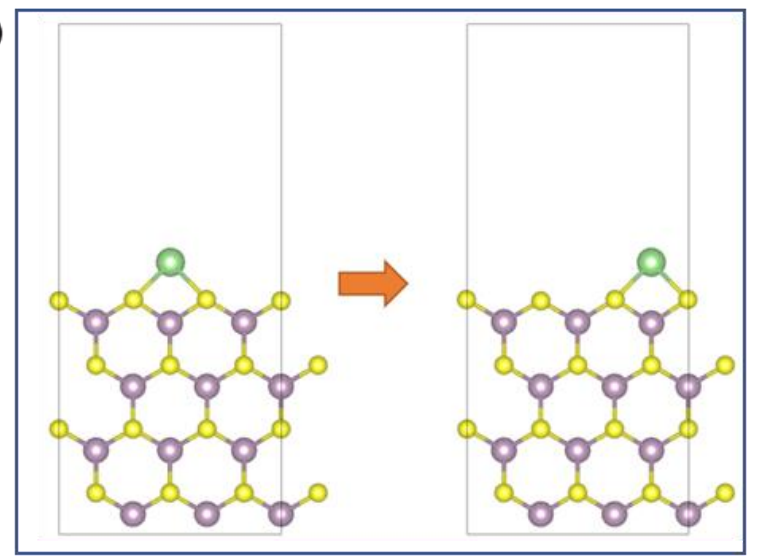

(c)
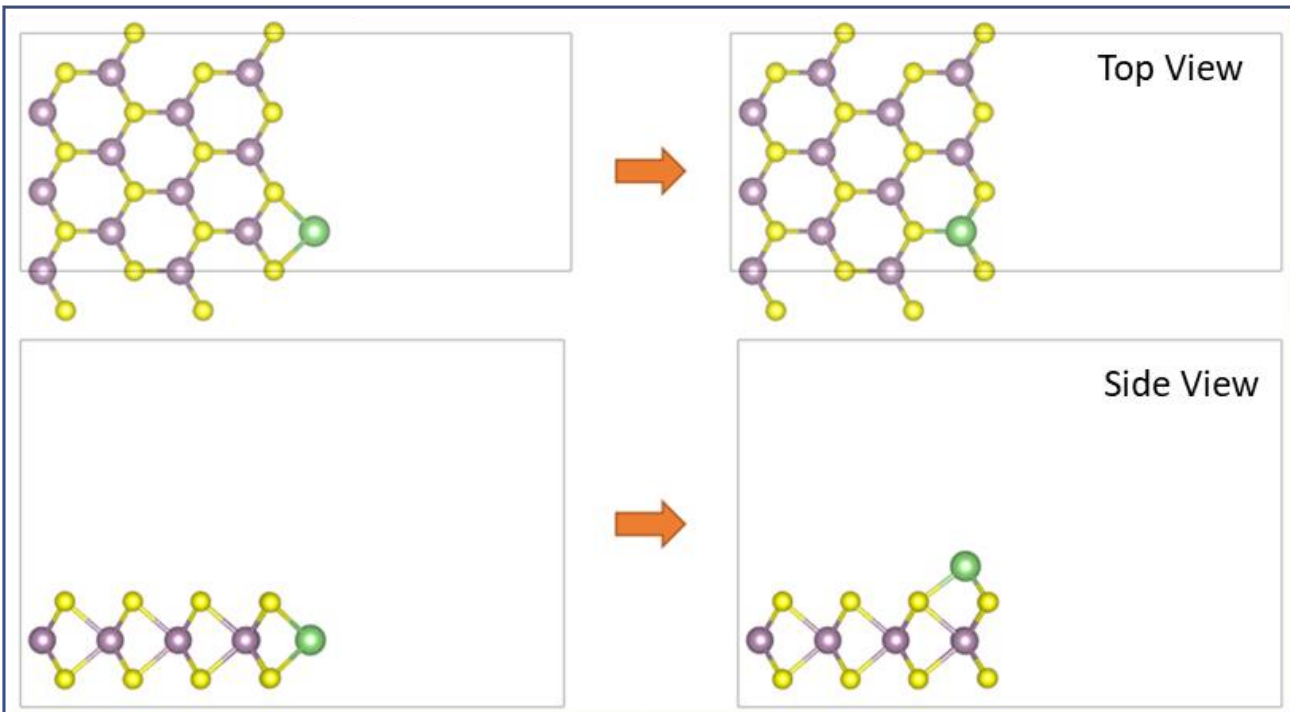

Figure S7. Diffusion pathway for (a) the surface (b) the edge and (c) the pathway conjoining the edge and surface, top and side views calculations. Purple and yellow spheres represent Mo and S atoms, respectively. Green is the diffusing alkali species. 


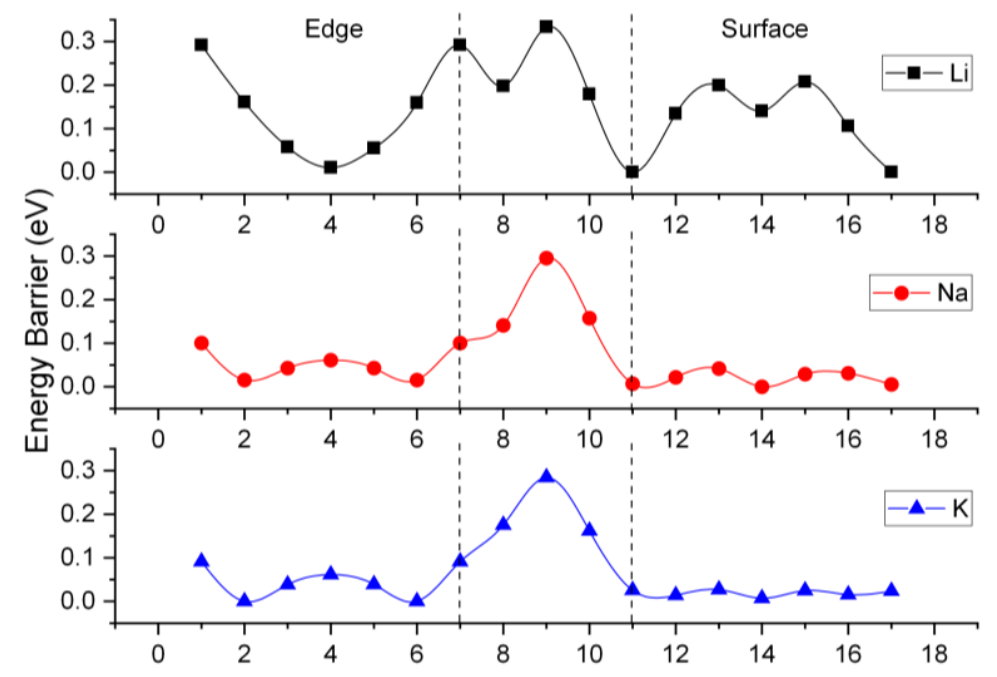

Figure S8. Diffusion behavior of Li (top), $\mathrm{Na}$ (middle), and K (bottom) along different pathways of a $2 \mathrm{H} \mathrm{MoS} 2$ monolayer flake shown in Figure S7. Numerical values for the barriers for each segment are summarized in Table $\mathrm{S} 2$. 
Table S2. Values for the diffusion barriers in $2 \mathrm{H} \mathrm{MoS}_{2}$ monolayer depicted in Figure S7.

\begin{tabular}{|l|l|l|l|}
\hline Species & $\begin{array}{l}\text { Edge barrier } \\
(\mathbf{e V})\end{array}$ & $\begin{array}{l}\text { Crossover barrier } \\
(\mathbf{e V})\end{array}$ & $\begin{array}{l}\text { Surface barrier } \\
(\mathbf{e V})\end{array}$ \\
\hline $\mathrm{Li}$ & 0.281 & 0.333 & 0.207 \\
\hline $\mathrm{Na}$ & 0.085 & 0.288 & 0.042 \\
\hline $\mathrm{K}$ & 0.091 & 0.259 & 0.020 \\
\hline
\end{tabular}




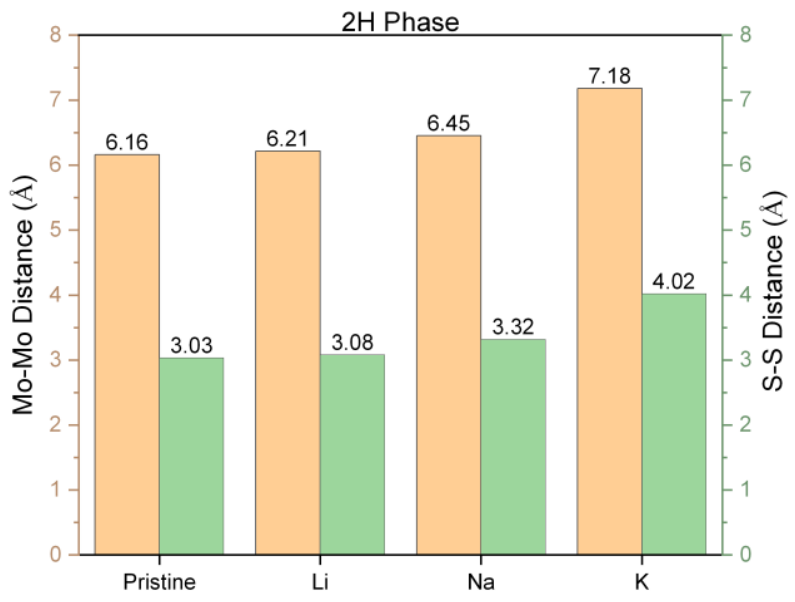

Figure S9. The interlayer spacing of $2 \mathrm{H} \mathrm{MoS}_{2}$ calculated for the pristine bulk material and with intercalating alkali ions at a concentration of $\mathrm{Mo}_{32} \mathrm{~S}_{64} \mathrm{X}_{1}$. This calculation allows the structure to relax around the intercalated ion and indicates that the equilibrium interlayer spacing increases significantly if $\mathrm{Na}$ or $\mathrm{K}$ ions are intercalated but changes very little for Li. HRTEM imaging (Figure 4) indicates that the spacing does not change with the introduction of the ion solution, providing evidence that $\mathrm{Na}$ and $\mathrm{K}$ ions are not diffusing through the interlayer of $\mathrm{MoS}_{2}$. 


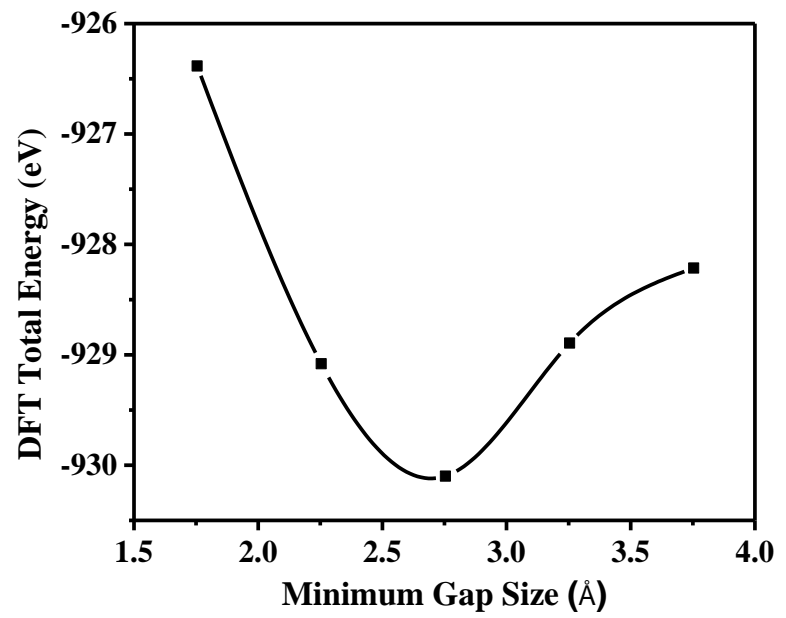

Figure S10. Energy curve associated with the separation distance of the two grains forming the grain boundary model used in the main text (Figure 3). In the real material, grain boundaries will exist with a greater separation than the optimum value but not smaller. It is unrealistic to model all possible geometric configurations using DFT, but the model chosen here is a reasonable reorientation of the confinement that exists within the polycrystal $\mathrm{MoS}_{2}$ observed in Figure S4. Even the smallest energy gap between the $\mathrm{MoS}_{2}$ grain boundaries can allow passage for even large ions such as $\mathrm{Na}$ and $\mathrm{K}$ ions to diffuse through the $\mathrm{MoS}_{2}$ membrane. 

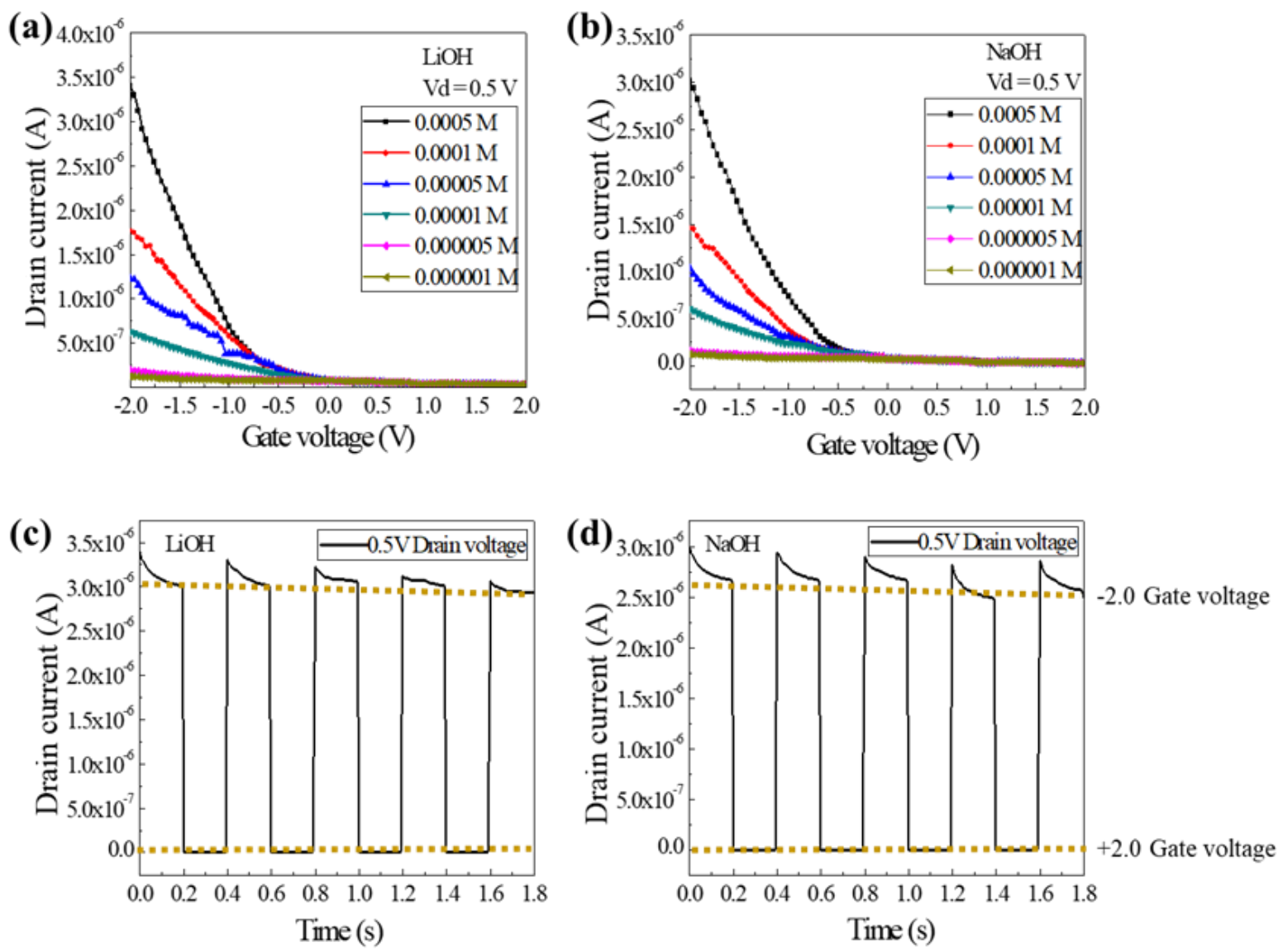

Figure S11. Ionic charge transfer characteristics ( $\mathrm{I}_{d}-\mathrm{V}_{\mathrm{g}}$ curve) of $\mathrm{MoS}_{2}$ film with (a) $\mathrm{LiOH}$ and (b) $\mathrm{NaOH}$ ionic solution from $1 \mu \mathrm{M}$ to $0.5 \mathrm{mM}$ concentration. Time traces of gate-induced (c) $\mathrm{LiOH}$ and (d) $\mathrm{NaOH}$ ionic current with the applied gate voltage of $+2 \mathrm{~V}$ and $-2 \mathrm{~V}$ showing the clear iongating effect. 

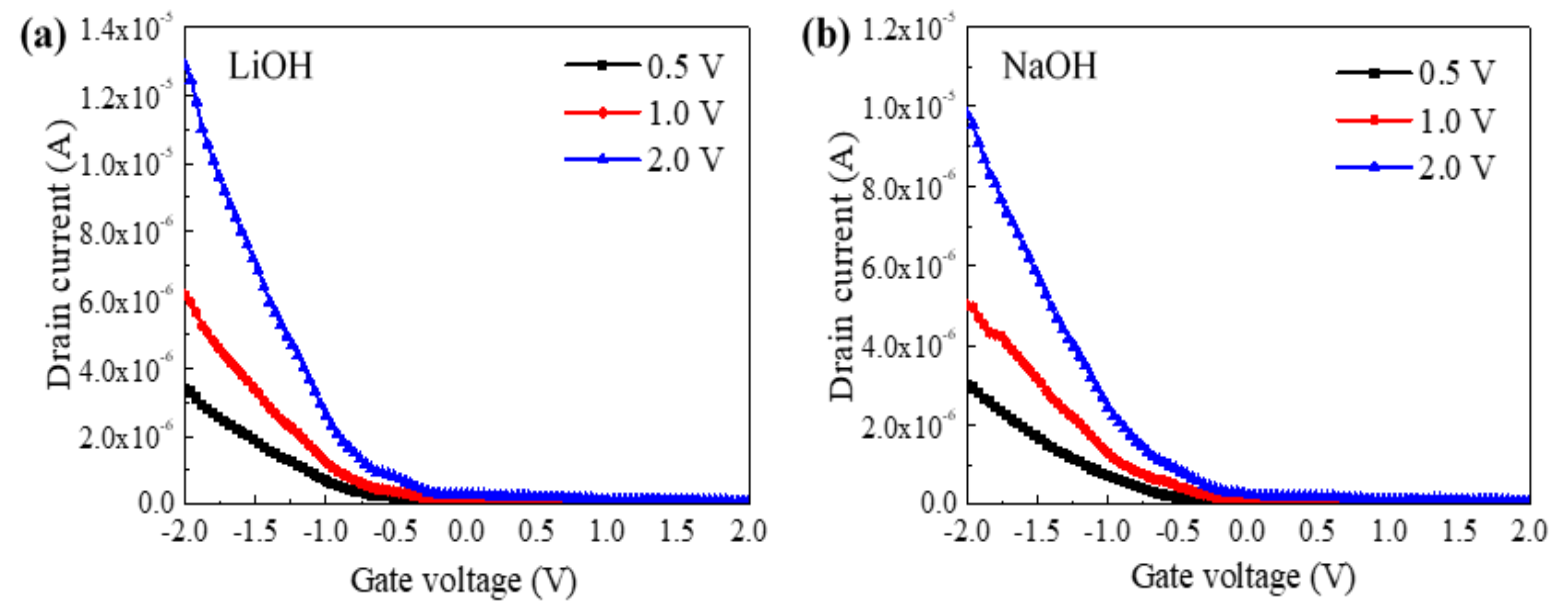

Figure S12. Ionic charge transfer characteristics ( $\mathrm{I}_{\mathrm{d}}-\mathrm{V}_{\mathrm{g}}$ curve) of $4.1 \mathrm{~nm}$-thick $\mathrm{MoS}_{2}$ with (a) $\mathrm{LiOH}$ and (b) $\mathrm{NaOH}$ ionic solution by applying drain voltage from $0.5 \mathrm{~V}$ to $2.0 \mathrm{~V}$. 

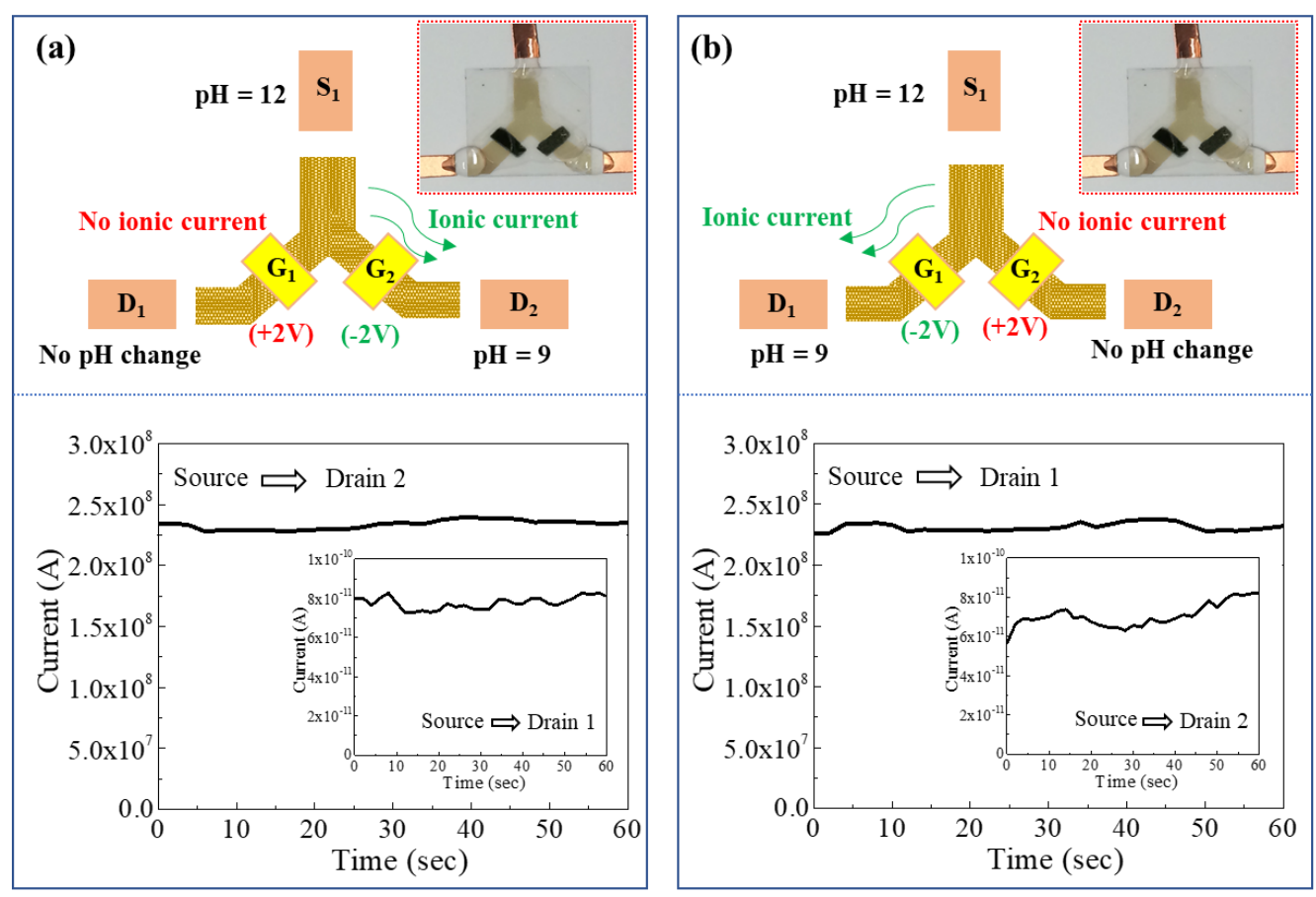

Figure S13. Schematics showing ion flow characteristics in a $\mathrm{Y}$-shaped $\mathrm{MoS}_{2}$ channel with applying gate voltage of (a) $\mathrm{V}_{\mathrm{g}}^{1}=+2 \mathrm{~V}$ and $\mathrm{V}^{2} \mathrm{~g}=-2 \mathrm{~V}$ and (b) $\mathrm{V}_{\mathrm{g}}{ }_{\mathrm{g}}=-2 \mathrm{~V}$ and $\mathrm{V}_{\mathrm{g}}^{2}=+2 \mathrm{~V}$, at constant $\mathrm{V}_{\mathrm{sd}}=0.5 \mathrm{~V}$. At $\mathrm{V}_{\mathrm{g}}=+2 \mathrm{~V}$, no ion flow occurs through the $\mathrm{MoS}_{2}$ film, while there is ion flow at $\mathrm{V}_{\mathrm{g}}$ $=-2 \mathrm{~V}$ resulting in $\mathrm{pH}$ change of the electrolyte solution. Our results confirm that ion flow can be effectively modulated by electrical gating. 


\section{REFERENCES}

(1) Verhoogen, J. Ionic Diffusion and Electrical Conductivity in Quartz. Am. Mineral. 1952, $37,637$.

(2) Lazzari, S.; Martini, M.; Paleari, A.; Spinolo, G.; Vedda, A. DC and AC Ionic Conductivity in Quartz: A New High Temperature Mechanism and a General Assessment. Nucl. Inst. Methods Phys. 1988, 32, 299.

(3) Qin, S.; Liu, D.; Wang, G.; Portehault, D.; Garvey, C. J.; Gogotsi, Y.; Lei, W.; Chen, Y. High and Stable Ionic Conductivity in 2D Nanofluidic Ion Channels between Boron Nitride Layers. J. Am. Chem. Soc. 2017, 139, 6314.

(4) Huggins, R. A. Simple Method to Determine Electronic Conductivity and Ionic Components of the Conductors in Mixed a Review. Ionics 2002, 8, 300.

(5) Dawson, D. C. Permeability and Conductance of Ion Channels A Primer. Molecular Biology of Membrane Transport Disorders 1996, 87-110.

(6) Gurarslan, A.; Jiao, S.; Li, T.-D.; Li, G.; Yu, Y.; Gao, Y.; Riedo, E.; Xu, Z.; Cao, L. van der Waals Force Isolation of Monolayer MoS 2. Adv. Mater. 2016, 28, 10055.

(7) Ma, H.; Shen, Z.; Ben, S. Understanding the Exfoliation and Dispersion of $\mathrm{MoS}_{2}$ Nanosheets in Pure Water. J. Colloid Interface Sci. 2018, 517, 204. 